\title{
Synthesis and Biological Activity of Drug Delivery System Based on Chitosan Nanocapsules
}

\author{
Mohamed Gouda ${ }^{1,2}{ }^{*}$, Usama Elayaan1,3, Magdy M. Youssef 1,3 \\ ${ }^{1}$ Department of Chemistry, College of Science, King Faisal University, Hofuf, Kingdom of Saudi Arabia \\ ${ }^{2}$ Textile Research Division, National Research Center, Cairo, Egypt \\ ${ }^{3}$ Department of Chemistry, Faculty of Science, Mansoura University, Mansoura, Egypt \\ Email: " mgoudaam@kfu.edu.sa, esmaeil2001@yahoo.com
}

Received 13 July 2014; revised 22 August 2014; accepted 17 September 2014

Academic Editor: William W. Yu, Rice University, USA

Copyright (C) 2014 by authors and Scientific Research Publishing Inc.

This work is licensed under the Creative Commons Attribution International License (CC BY).

http://creativecommons.org/licenses/by/4.0/

(c) (i) Open Access

\begin{abstract}
Chitosan nanocapsules containing naproxen as an active ingredient were synthesized by ionic gelation method in presence of polyanion tripolyphosphate as a crosslinker. The morphology and diameter of the prepared chitosan nanoparticles was characterized using scanning electron microscopy and transition electron microscopy. Different factors affecting on the size diameter of chitosan nanoparticles such as stirring time and temperature, $\mathrm{pH}$ values as well as chitosan concentration were studied. Different factors affecting on the immobilization of naproxen into chitosan nanoparticles such as time, temperature and $\mathrm{pH}$ values were optimized. Synthesized naproxen/chitosan nanocapsules were assessed against both Gram positive bacterial strain such as $\mathrm{Ba}$ cillus subtilis and Staphylococcus aureus and Gram negative bacterial strain such as Pseudomonas aeruginosa and Escherichia coli. Also, the antifungal activity of the naproxen/chitosan nanocapsules against Saccharomyces cerevisiae was demonstrated. Super oxide dismutase like activity of naproxen/chitosan nanocapsules will be determined.
\end{abstract}

\section{Keywords}

Chitosan, Naproxen, Nanocapsules, Drug Delivery Systems, Antimicrobial, Antioxidant, DNA Degradation

\footnotetext{
"Corresponding author.
}

How to cite this paper: Gouda, M., Elayaan, U. and Youssef, M.M. (2014) Synthesis and Biological Activity of Drug Delivery System Based on Chitosan Nanocapsules. Advances in Nanoparticles, 3, 148-158. 


\section{Introduction}

Chitosan, poly[ $\beta$-(1-4)-linked-2-amino-2-deoxy-D-glucose], is the $N$-deacetylated product of chitin [1]. The difference between chitosan and chitin is only in the functional group situated at carbon- 2 of the monomeric unit. Owing to the presence of free amino groups in chitosan, the solubility and reactivity of this polymer are greater than those of chitin [2]. In addition, chitosan has many significant biological and chemical properties: it is biodegradable, biocompatible, bioactive, and polycationic [3]. Thus, it has been widely used in many industrial and biomedical aspects, including in enzyme immobilization, and as carrier for controlled drug delivery [4]-[7]. In addition, chitosan is economically attractive because chitin is the most abundant natural polymer after cellulose. However, chitosan is macromolecular, which significantly marks its application. To overcome this drawback, the use of chitosan fabricated nano/submicron chitosan is effective. In recent years, nanotechnology has showed significant attractiveness for the preparation of drug carriers. Under the scale of nano, nanomaterials have characteristics such as magnetism and large surface area. These characteristics are favorable for drug immobilization. Many studies have mainly reported the preparation of chitosan nanoparticles and their applications in the carrier of drugs [8] [9].

Hollow nanocapsules in the fields of pharmaceutics, cosmetic, food, textile, adhesive, agricultural industry, artificial cells, and protection of proteins, enzymes, DNA, and catalysis have been widely used [10] [11]. All these based on their isolating property, large inner volume, and tunable permeability [12] [13]. To obtain the nanocapsules with multipurpose properties, new efforts are always tried to explore various techniques for fabrication. The template method as a common method to prepare nanocapsules often needs a template such as micelles [14], calcium carbonate [15], polyurea [16], and emulsion droplets [17]. In the template method, the target material is precipitated or polymerized on the surface of the template. Then, the template is removed to form a cavity, leading to a hollow sphere structure [18] [19]. Another common method to fabricate nanocapsules by the layer by-layer assembly [20] [21], multilayer nanocapsules with ultrathin wall thickness and tunable wall structures and properties has been fabricated [22] [23]. Furthermore, naproxen is a nonsteroidal antiinflammatory drugs. In the body, it works by reducing the hormones which causes inflammation and pain.

Naproxen (Figure 1) [24], is one of the most commonly used propionic acid derivatives for the treatment of pain, joint swelling and symptoms of arthritis, it is worked by blocking the action of cyclooxygenase involved in the production of prostaglandins that are produced in response to injury or certain diseases and cause pain, swelling and inflammation. However it's causing some gastrointestinal side effects possibly caused by the free acidic group present. Because of their distinctive structural features and wide range of pharmacological activities, hydrazones have attracted enormous interest especially in medicinal chemistry [25]. Moreover, naproxen has shown anti-mycobacterial activities when tested in vitro [26] [27]. The objective of the present study is to synthesize and characterize chitosan nanocapsules using ionic gelation method in presence of polyanion tripolyphosphate as a cross-linker and to immobilize the naproxen as an active ingredient. The prepared nanocapsules will be characterized using ESM and TEM spectroscopy. Biological activities of prepared nanocapsules as antimicrobial activity against both gram positive and gram negative bacterial strains, DNA inhibition as well as super oxide radical inhibition will be evaluated.

\section{Experimental Methods}

\subsection{Materials}

Chitosan low molecular weight (70,000 Daltons) with deacetylation degree of 85\% and sodium triphosphate (TPP) were purchased from Aldrich Co., naproxen was obtained from Aldrich Co., acetic acid and ethanol (99.7\%) were obtained from Merck Co.

\subsection{Preparation of Chitosan Nanoparticles in Water Phase}

Chitosan nanoparticles were prepared according to the ionotropic gelation process [28]. Various concentrations<smiles>COc1ccc2cc(C(C)C(=O)O)ccc2c1</smiles>

Figure 1. Structure of naproxen. 
of chitosan $(0.1 \%, 0.5 \%, 1.0 \%, 1.5 \%$ and $2 \%)$ were dissolved in acetic aqueous solution. At room temperature, $20 \mathrm{~mL}$ of various concentrations of TPP solution $(0.1,0.50,1.0,1.5$ and $2.0 \mathrm{mg} / \mathrm{mL}$ ) were added to $40 \mathrm{~mL}$ of chitosan solution at different $\mathrm{pH}$, respectively. The mixtures were stirred with high speed ultrasonic stirrer at different time and temperatures. Prepared chitosan nanoparticles were filtered off from the solutions by centrifuge with 11,000 rpm. Filtered chitosan nanoparticles were dried in an oven at $50^{\circ} \mathrm{C}$ for $30 \mathrm{~min}$.

\subsection{Characterization of Chitosan Nanoparticles}

The morphologic characterization of chitosan nanoparticles was evaluated using a scanning electron microscopy (JSM-5610LV; JEOL, Japan). Particle size diameter of the prepared chitosan nanoparticles was evaluated using transmission electron microscopy (TEM) TEM (ZEISS-EM-10-GERMANY).

\subsection{Immobilization of Naproxen}

Ten milliliters of chitosan nanoparticle solution containing $1.0 \mathrm{mg}$ of dry chitosan nanoparticles in the tube was incubated in a water bath for $30 \mathrm{~min}$. Then $1.0 \mathrm{~mL}$ of $1.0 \mathrm{mg} / \mathrm{mL}$ naproxen was added to this tube, and the mixture was stirred with ultrasonic stirrer for different times $(10,20,30$, and $40 \mathrm{~min})$ at different temperatures $\left(40^{\circ} \mathrm{C}\right.$, $50^{\circ} \mathrm{C}, 60^{\circ} \mathrm{C}$ and $70^{\circ} \mathrm{C}$ ) and different $\mathrm{pH}$ values (2.0, 3.0, 4.0, 5.0, 6.0 and 7.0). Naproxen immobilized on chitosan nanoparticles was removed by centrifugation at $11000 \mathrm{rpm}$, and the supernatant was collected to calculate the residual amount of naproxen.

\subsection{Determination of Naproxen Concentration}

Visible spectrophotometric method has been developed for the determination of naproxen concentration according to reported method [29]. The developed method is based on reaction of naproxen with phenol red. It was quantified spectrophotometrically at their absorption maximum at $422 \mathrm{~nm}$.

\section{Preparation of Standard Naproxen Solution}

Standard solution of naproxen $(1000 \mu \mathrm{g} / \mathrm{ml})$ was prepared by dissolving $100 \mathrm{mg}$ in methanol and diluting to the mark in a $100 \mathrm{ml}$ volumetric flask. Working standard solution of $100 \mu \mathrm{g} / \mathrm{ml}$ was prepared by further dilution of the above standard stock solution

Phenol Red Method: Aliquots of the working standard solution of naproxen (60 - 80 $\mu \mathrm{g} / \mathrm{ml})$ were prepared and from that $1 \mathrm{ml}$ of sample was accurately measured and transferred into a series of volumetric flasks by means of a micro burette. To each of the above aliquots, $1 \mathrm{ml}$ of $100 \mu \mathrm{g} / \mathrm{ml}$ of phenol red solution in methanol was added and mixed thoroughly. The volume was brought up to $5 \mathrm{ml}$ mark with methanol, mixed thoroughly and after 10 min absorbance of each species was measured at $422 \mathrm{~nm}$ against reagent blank. A calibration curve was constructed by plotting the absorbance against the concentration of the drug.

\subsection{Biological Activity of Naproxen/Chitosan Nanocapsules}

\subsubsection{Agarose Gels Electrophoresis}

The chitosan, naproxen, and naproxen/chitosan nanocapsule $(50 \mu \mathrm{g})$ were added individually to $1 \mu \mathrm{g}$ of the DNA isolated from E. coli strain W3110 [30]. The samples were incubated for $1 \mathrm{~h}$ at $37^{\circ} \mathrm{C}$. The DNA was analyzed by using horizontal agarose gels electrophoresis. The electrophoresis was performed using $0.7 \%(\mathrm{w} / \mathrm{v})$ agarose gels in TAE buffer ( $5 \mathrm{mM}$ sodium acetate, $1 \mathrm{mM}$ EDTA and $0.04 \mathrm{M}$ Tris- $\mathrm{HCl} \mathrm{pH} \mathrm{7.9).} \mathrm{The} \mathrm{agarose} \mathrm{gels}$ were stained with ethidium bromide $(0.5 \mu \mathrm{g} / \mathrm{ml})$ and the DNA was visualized on a UV transilluminator [31].

\subsubsection{Polyacrylamide Gel Electrophoresis}

Egg Albumin $(5 \mu \mathrm{g})$ was treated with the chitosan, naproxen, and naproxen/chitosan nanocapsule $(10 \mu \mathrm{g})$ individually. The reaction mixtures were incubated for $1 \mathrm{~h}$ at $37^{\circ} \mathrm{C}$. The protein samples were examined by using vertical one dimensional SDS-polyacrylamide gel electrophoresis according to the method of Laemmli [32].

\subsubsection{Antibacterial and Antifungal Activities}

The antimicrobial investigation of chitosan, naproxen, and naproxen/chitosan nanocapsule was carried out using cup diffusion technique [33]. The test was carried out against the Gram-negative bacterial strains Pseudomonas aeruginosa (P. aeruginosa) and Escherichia coli (E. coli), the Gram-positive bacterial strains Bacillus subtilis (B. 
subtilis) and Staphylococcus aureus (S. aureus) and the fungal strain Saccharomyces cerevisiae (S. cerevisiae). The tested chitosan, naproxen and naproxen/chitosan nanocapsule were dissolved in Dimethyl sulfoxide (DMSO) at concentration I mg/ml. The Luria-Bertani Agar (LBA) Medium (10 g bacto-tryptone, $5 \mathrm{~g}$ yeast extract, $20 \mathrm{~g}$ agar, and $10 \mathrm{~g} \mathrm{NaCl}$ in 1 Liter de-ionized water) was made for inoculation and bacterial growth. An aliquot of the solution of the tested naproxen/chitosan nanocapsule equivalent to $100 \mu \mathrm{g}$ was placed separately in cups, cut in the agar. The LBA dishes were incubated for 24 hours at $37^{\circ} \mathrm{C}$ and the resulting inhibition zones were measured. From the inhibition zone diameter data analysis, the antimicrobial activity against the Gram-negative, Gram-positive bacteria and the fungal were determined.

\subsubsection{Determination of Super Oxide Dismutase (SOD) Like Activity}

The chitosan, naproxen and naproxen/chitosan nanocapsule were assayed for super oxide dismutase enzyme like activity [34]. SOD like activity of chitosan, naproxen and naproxen/chitosan nanocapsule was assayed by using phenazenmethosulphate (PMS) to generate a superoxide anion radicals at $\mathrm{pH}=8.3$ (phosphate buffer). Reduction of nitrobluetetrazolium (NBT) to form blue formazan was used as an indicator of superoxide production and followed spectrophotometrically at $560 \mathrm{~nm}$. The addition of PMS $\left(9.3 \times 10^{-5} \mathrm{M}\right)$ to a solution of NBT $\left(3 \times 10^{-5}\right.$ $\mathrm{M})$, NADH $\left(4.7 \times 10^{-4} \mathrm{M}\right)$ and phosphate buffer (final volume of $\left.1 \mathrm{ml}\right)$ caused a change of OD $(\Delta 1) 560 \mathrm{~nm}$ per $4 \mathrm{~min}$. The reactions in blank samples and in the presence of chitosan, naproxen and naproxen/chitosan nanocapsule were measured. For comparative purposes, the activity of native horseradish superoxide dismutase (HR SOD) has also been determined.

\section{Results and Discussion}

\subsection{Preparation of Chitosan Nanoparticles}

\subsubsection{Effect of Stirring Time on Size of Chitosan Nanoparticles}

To study the influence of stirring time on the size of chitosan nanoparticles, stirring time was different from 10 to $40 \mathrm{~min}$ using ultrasonic stirrer at 21,000 rpm; the results are shown in Figure 2. It can be seen that, the particle size of prepared chitosan nanoparticles decreases with increasing of stirring time. Stirring time for 10 min, the particle size was $100-120 \mathrm{~nm}$ and by increasing of stirring time for $40 \mathrm{~min}$ the size of prepared nanoparticles became $30-60 \mathrm{~nm}$. This trend could be explained by the energy transfer differences for different stirring times [17] [18].

\subsubsection{Effect of Temperature on Size of Chitosan Nanoparticles}

Figure 3 shows the effect of temperature on the size of chitosan nanoparticles. The size of chitosan nanoparticles almost did not change from $30^{\circ} \mathrm{C}$ to $60^{\circ} \mathrm{C}$. However, above $60^{\circ} \mathrm{C}$, the solution became transparent, and chitosan nanoparticles were not fabricated. An explanation for this phenomenon is that the chitosan molecular chain might be cut short and fabrication was not done under the same conditions.

\subsubsection{Effect of pH on Size of Chitosan Nanoparticles}

Chitosan nanoparticles were successfully prepared by ionic gelation method. Figure 4 shows the effects of pH on particle size. The mean diameter of chitosan nanoparticles decrease with increases of $\mathrm{pH}$. This could be related to different chitosan molecular conformation with changing $\mathrm{pH}$ before nanoparticle formation. Because the

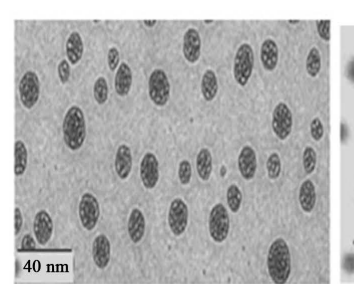

(a)

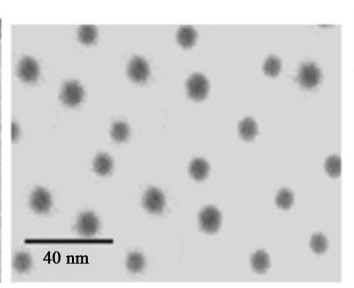

(b)

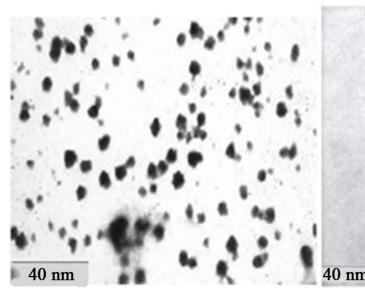

(c)

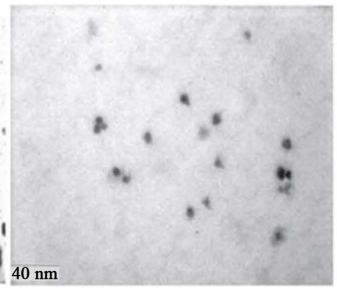

(d)

Figure 2. TEM micrograph of prepared chitosan nanoparticles at different stirring rate (a) 10 min; (b) 20 min; (c) 30 min and (d) 40 min. Using chitosan concentration; $0.1 \%$ with TPP concentration; $0.1 \mathrm{mg} / \mathrm{mL}$, at $\mathrm{pH} ; 7.0$ and at temperature; $30^{\circ} \mathrm{C}$. 


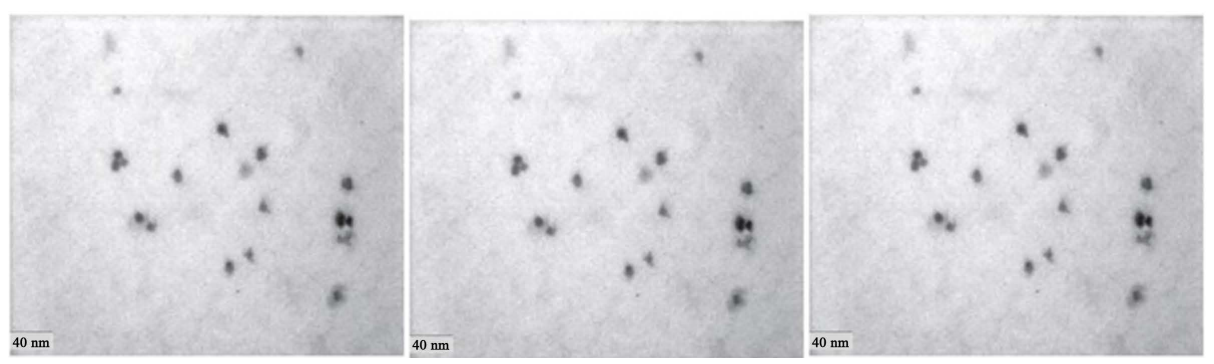

(a)

(b)

(c)

Figure 3. TEM micrograph of prepared chitosan nanoparticles at different temperature (a) $30^{\circ} \mathrm{C}$; (b) $40^{\circ} \mathrm{C}$; (c) $60^{\circ} \mathrm{C}$. Using chitosan concentration; $0.1 \%$ with TPP concentration; $0.1 \mathrm{mg} / \mathrm{mL}$, at $\mathrm{pH} ; 7.0$ and for stirring time; $40 \mathrm{~min}$.

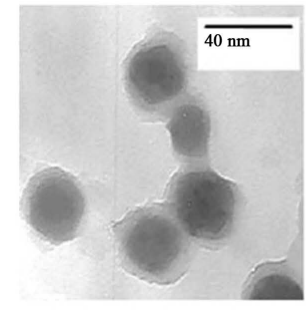

(a)

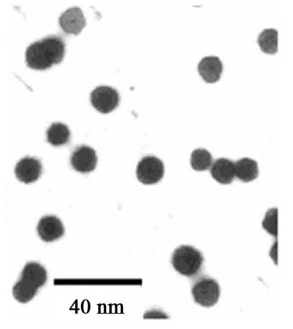

(b)

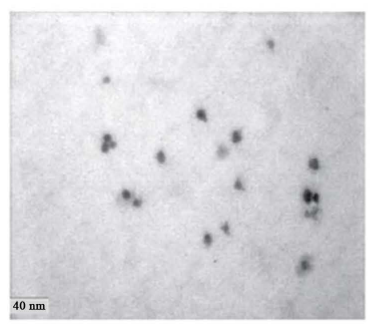

(c)

Figure 4. TEM micrograph of the prepared chitosan nanoparticles using different $\mathrm{pH}$ values $(\mathrm{a}) \mathrm{pH}=$ 3.0; (b) $\mathrm{pH}=5.0$ and (c) $\mathrm{pH}=7.0$. Using chitosan concentration; $0.1 \%$ with TPP concentration; 0.1 $\mathrm{mg} / \mathrm{mL}$, at temperature $30^{\circ} \mathrm{C}$ and for stirring time; $40 \mathrm{~min}$.

isoelectric point of chitosan was 6.8, the majority of amino groups were protonated to form an extended molecular chain in acid solution owing to strong repulsion existing among positively charged ammonium groups at low $\mathrm{pH}$ (3.0) [16]. A more extended spherical shape was formed on the addition of TPP solution. With an increase in $\mathrm{pH}$ (from 3.0 to 7.0), positive charges would be neutralized with gradual de-protonation of ammonium groups, resulting in a less extended molecular chain of chitosan to form uniform small nanoparticles.

\subsubsection{Effect of Chitosan Concentrations on the Size of Chitosan Nanoparticles}

The results in Figure 5 show that the formation of nanoparticles at different chitosan concentrations $(0.1 \%$, $0.50 \%, 1.0 \%, 1.5 \%$ and $2.0 \%$ ) was possible only within some moderate concentrations of chitosan and TPP. Some opalescent suspension was formed between TPP solution of $1.0-2.0 \mathrm{mg} / \mathrm{ml}$. It has been observed that the highly viscous nature of the gelation medium will aggregate the formed nanoparticles [15]. Thus, it was supposed that a relatively lower viscosity of chitosan with a lower concentration promoted the formation of nanoparticles between chitosan and TPP.

\subsection{SEM of Prepared Chitosan Nanoparticles}

Figure 6 presents scanning electron micrographs of nanoparticles prepared by ionotropic gelation process. Spherical nanoparticles were formed spontaneously upon the incorporation of TPP solution to the chitosan solution under ultrasonic stirring. Chitosan nanoparticles are obtained by ionic gelation which is a simple process, where particles are formed by means of electrostatic interactions between the positively charged chitosan chains and polyanions (TPP) employed as cross linkers.

\subsection{Conditions of Naproxen Immobilization}

\subsubsection{Effect of Time and Temperature on Immobilization}

Naproxen was immobilized on chitosan nanoparticles at different times and temperature. The residual naproxen of the solution was determined using the method described above. As shown in Table 1, the optimal immobilization time and temperature was $15 \mathrm{~min}$ at $60^{\circ} \mathrm{C}$. When the immobilization time was more than $15 \mathrm{~min}$ and 


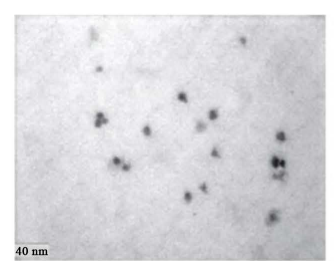

(a)

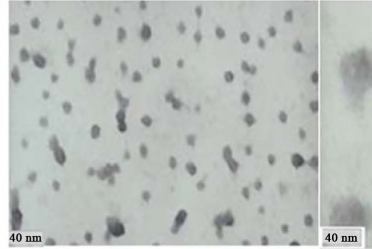

(b)

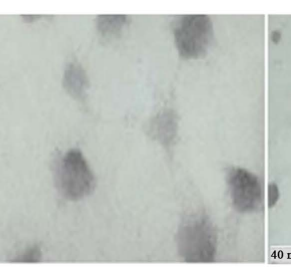

(c)

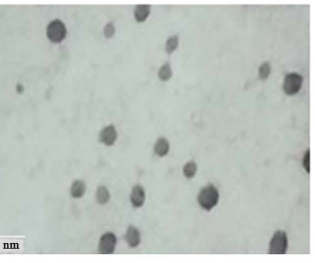

(d)

Figure 5. TEM micrograph of chitosan nanoparticles using different chitosan concentrations, (a) $0.1 \%$; (b) $0.5 \%$; (c) $1.0 \%$ and (d) $2.0 \%$.

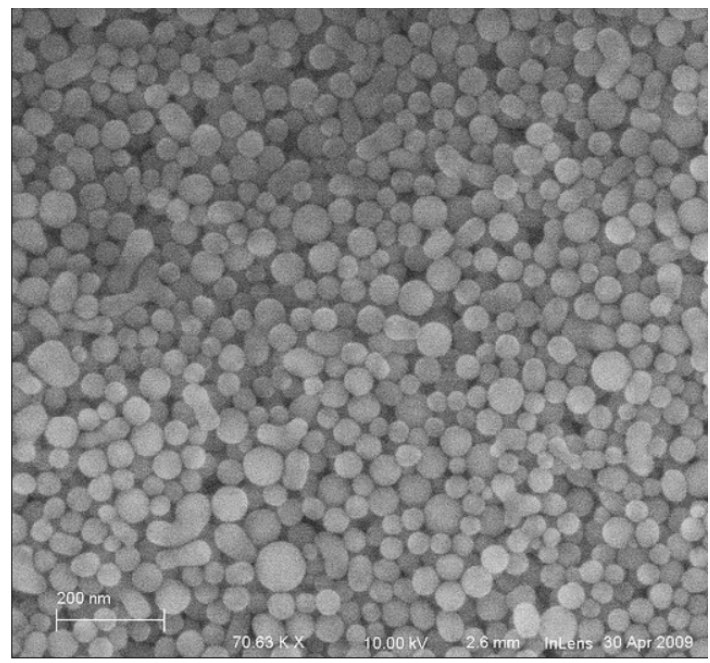

Figure 6. SEM micrograph of chitosan nanoparticles prepared using $0.1 \%$ of chitosan with $0.1 \mathrm{mg} / \mathrm{mL}$ TPP at $30^{\circ} \mathrm{C}$ stirring time $40 \mathrm{~min}$ at $\mathrm{pH} 7.0$.

Table 1. Residual concentration of naproxen (mg/gm. sample) at different time and temperature using $0.1 \mathrm{gm}$ naproxen, $0.1 \mathrm{~g} \%$ chitosan with $0.1 \mathrm{mg} / \mathrm{ml} \mathrm{TPP}$.

\begin{tabular}{ccccc}
\hline \multirow{2}{*}{ Time (min) } & \multicolumn{4}{c}{ Naproxen concentration (mg/gm. sample) } \\
\cline { 2 - 4 } & $40^{\circ} \mathrm{C}$ & $50^{\circ} \mathrm{C}$ & $60^{\circ} \mathrm{C}$ & $70^{\circ} \mathrm{C}$ \\
\hline 5 & 0.18 & 0.16 & 0.13 & 0.15 \\
10 & 0.15 & 0.12 & 0.1 & 0.11 \\
15 & 0.1 & 0.08 & 0.05 & 0.07 \\
20 & 0.1 & 0.08 & 0.04 & 0.07 \\
25 & 0.1 & 0.08 & 0.04 & 0.07 \\
\hline
\end{tabular}

temperature was higher than $60^{\circ} \mathrm{C}$, the relative immobilization rate did not increase any more. This is attributed to that, at temperature higher than $60^{\circ} \mathrm{C}$ for time more than 15 min the prepared chitosan nanoparticles were aggregated and this may be effect on the immobilization velocity because the immobilization rate with chitosan nanoparticles was very quick because of their larger specific surface area of contact.

\subsubsection{Effect of pH on Immobilization}

Naproxen was immobilized on chitosan nanoparticles at different $\mathrm{pH}$ values in phosphate buffer solutions (pH 7.2). The residual naproxen of solution was determined as the method described above. As shown in Figure 7, the relative immobilization rate increases with increasing the $\mathrm{pH}$ of the solution up to 5 and then decreases with increasing the $\mathrm{pH}$ value more than 5 . This is may be attributed to that, when the solution $\mathrm{pH}$ was more than 5 , the chitosan nanoparticles began to accumulate into larger chitosan microparticles which precipitated in the solution and the relative immobilization rate began to decrease. 


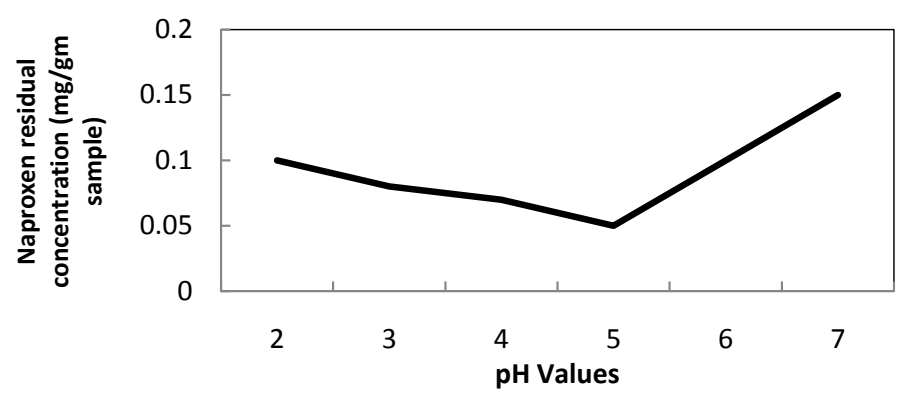

Figure 7. Effect of different $\mathrm{pH}$ values on immobilization of Naproxen into chitosan nanoparticles using $0.1 \mathrm{gm}$ naproxen, $0.1 \mathrm{gm}$ chitosan with $0.1 \mathrm{mg} / \mathrm{ml} \mathrm{TPP}$ at $60^{\circ} \mathrm{C}$ for $15 \mathrm{~min}$.

\subsection{Biological Activity}

\subsubsection{Effect of Chitosan, Naproxen, and Chitosan Nanoparticles on DNA and Protein}

The degradation effect of $50 \mu \mathrm{g}$ of the chitosan, naproxen and naproxen/chitosan nanocapsule on the DNA in vitro is illustrated in Figure 8. The negative control (only DNA) and the positive control (DNA in DMSO) do not exhibit any degradation on DNA through the incubation period as illustrated in Figure 8 lanes 1 and 2, respectively. Chitosan has no degradation effect on the DNA as shown in Figure 8 lane 3. Naproxen has a significant degradation effect on the DNA as represented in Figure 8 lane 4. A complete degradation effect was exhibited by naproxen/chitosan nanocapsule as illustrated in Figure 8 lane 5. Therefore, the and naproxen/chitosan nanocapsule can be used as a promising anti-tumor agent in vivo to inhibit the DNA replication in the cancer cells and not allow the tumor for further growth. More work in vivo requirements to carry out to clarify their complete role. Further biochemical studies to reveal the effect of the chitosan, naproxen, and naproxen/chitosan nanocapsule on bovine serum albumin (BSA) as a high molecular weight biological compound was carried out. The result of the chitosan, naproxen, and naproxen/chitosan nanocapsule on the BSA was represented in Figure 9. The BSA and BSA in DMSO were utilized as controls as shown Figure 9 lanes 1 and 2, respectively. Chitosan has no effect on the BSA as compared to the control and represented in Figure 9 lane 3. While, naproxen exhibited a little degradation effect on the BSA as shown in Figure 9 lane 4. However, the naproxen/chitosan nanocapsule exhibited a partial degradation effect on the BSA as shown in Figure 9 lane 5.

The naproxen alone and naproxen/chitosan nanocapsule are able to interact with nucleophilic molecules including DNA. In the present study, naproxen/chitosan nanocapsule were demonstrated to degrade the in vitro DNA. The naproxen/chitosan nanocapsule interact with DNA forming inter-and intra-strand adducts, hindering DNA replication, leading to cell cycle arrest and apoptosis.

\subsubsection{Antioxidant Activity of Chitosan, Naproxen, and Naproxen/Chitosan Nanocapsule}

The SOD mimics like activity of chitosan, naproxen and naproxen/chitosan nanocapsule is represented in Table 2. Chitosan, naproxen, and naproxen/chitosan nanocapsule exhibit a significant SOD like activity and cause an inhibition percent of $78.01 \%, 66.61 \%$ and $72.07 \%$, respectively. Chitosan, naproxen and naproxen/chitosan nanocapsule inhibited superoxide radical generation. Maintaining the equilibrium between the rate of radical generation and the rate of radical scavenging is an essential part of biological homeostasis. Therefore, it is suggested that the inhibition of superoxide radical generation by chitosan, naproxen and naproxen/chitosan nanocapsule is attributable to their free radical scavenging activity.

\subsubsection{Antimicrobial Activity of Chitosan, Naproxen and Naproxen/Chitosan Nanocapsule}

Ampicillin, a broad-spectrum antibiotic, was utilized as a positive control for this test. The results of the antimicrobial test of chitosan, naproxen and naproxen/chitosan nanocapsule against Gram-negative ( $P$. aeruginosa and E. coli) and Gram-positive (B. subtilis and S. aureus) bacterial strains are summarized in Table 3. The naproxen/chitosan nanocapsule has maximal antimicrobial activity with inhibition zone diameter against $E$. coli $27 \mathrm{~mm}$, P. aeruginosa $26 \mathrm{~mm}, B$. subtilis $23 \mathrm{~mm}$, S. aureus $27 \mathrm{~mm}$ and S. cerevisiae $24 \mathrm{~mm}$ as represented in Table 3. Also, Chitosan showed a wide spectrum of antimicrobial activity with inhibition zone diameter against $E$. coli $25 \mathrm{~mm}, P$. aeruginosa $23 \mathrm{~mm}, B$. subtilis $24 \mathrm{~mm}, S$. aureus $24 \mathrm{~mm}$ and $S$. cerevisiae $20 \mathrm{~mm}$ as represented in 


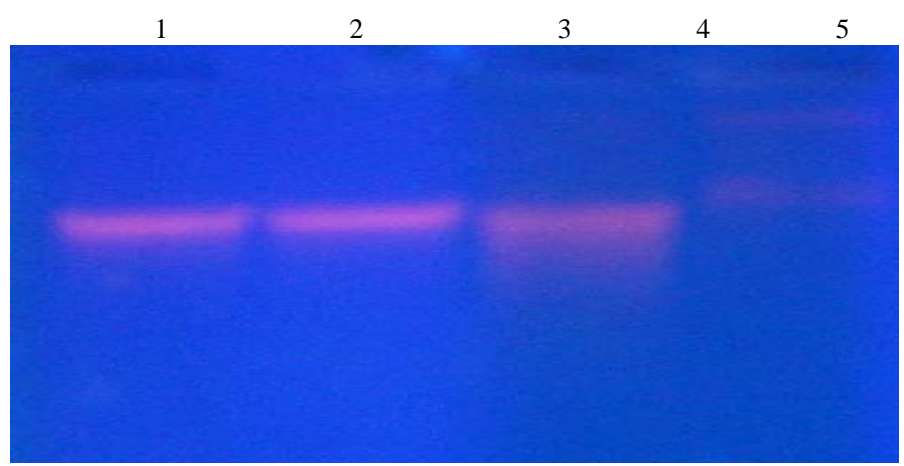

Figure 8. A figure showing the degradation effect of chitosan and naproxen chitosan nanoparticles on the DNA isolated from $E$. coli strain W3110.

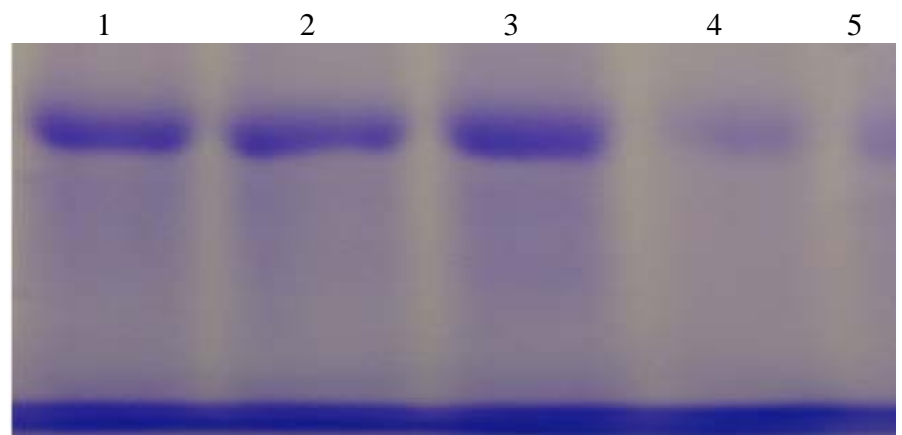

Figure 9. A figure showing the degradation effect of the chitosan, naproxen, and and naproxen/chitosan nanocapsule on the bovine serum protein.

Table 2. Superoxide (SOD) like activity of chitosan, naproxen and naproxen/chitosan nanocapsule as antioxidant enzyme.

\begin{tabular}{rcc}
\hline & $\Delta$ through 4 min & \% inhibition \\
Control & 0.623 & - \\
HR SOD & 0.158 & 74.64 \\
Chitosan & 0.137 & 78.01 \\
Naproxen & 0.208 & 66.61 \\
Naproxen/chitosan nanocapsule & 0.174 & 72.07 \\
\hline
\end{tabular}

$\%$ inhibition $=(\Delta$ Control $-\Delta$ Test $/ \Delta$ Control $) \times 100$.

Table 3. Effect of chitosan, naproxen, and chitosan nanoparticles on some microorganisms "the results expressed as zone inhibition in mm diameter”.

\begin{tabular}{cccccc}
\hline & E. coli & P. aeruginosa & S. aureus & B. subtilis & S. cerevisiae \\
Ampicillin & 22 & 18 & 23 & 19 & 20 \\
Chitosan & 25 & 23 & 24 & 9 & 13 \\
Naproxen & 14 & 11 & 9 & 23 & 24 \\
Naproxen/chitosan nanocapsule & 27 & 26 & 27 &
\end{tabular}


Table 3. However, the naproxen exhibited a moderate antimicrobial activity as the inhibition zone diameter against the tested microorganisms compared to the wide spectrum standard antibiotic ampicillin as illustrated in Table 3.

\section{Conclusion}

Ionic gelation technique was used as an efficient processing method to synthesize of chitosan nanocapsules containing naproxen as an active agent. Characterization and evaluation of these synthesized products were undertaken. The synthesis involved preparation of chitosan nanoparticles cross linked with polyanion tripolyphosphate (TPP) and the factors affecting on the diameter of prepared chitosan nanoparticles were optimized and the major conclusion arrived at from these studies are given under: 1) The particle size of prepared chitosan nanoparticles decreases with increasing of stirring time. Stirring time for $10 \mathrm{~min}$, the particle size was $100-120 \mathrm{~nm}$ and by increasing of stirring time for 40 min the size of prepared nanoparticles became $30-60 \mathrm{~nm}$. 2) The size of chitosan nanoparticles almost did not change from $30^{\circ} \mathrm{C}$ to $60^{\circ} \mathrm{C}$. However, above $60^{\circ} \mathrm{C}$, the solution became transparent, and chitosan nanoparticles were not fabricated. 3) The mean diameter of chitosan nanoparticles decreases with increasing of $\mathrm{pH}$, indicating an influence of $\mathrm{pH}$ on particle size. 4) The formation of nanoparticles at different chitosan concentrations $(0.1 \%, 0.50 \%, 1.0 \%, 1.5 \%$ and $2.0 \%)$ was possible only within some moderate concentrations of chitosan and TPP. Some opalescent suspension was formed between TPP solution of 1.0 $2.0 \mathrm{mg} / \mathrm{ml}$. Different factors affecting on the immobilization of naproxen into chitosan nanoparticles were studied and the major conclusion arrived at from these studies are given as follows: 1) The optimal immobilization time and temperature was $15 \mathrm{~min}$ at $60^{\circ} \mathrm{C}$. 2) The optimal immobilization $\mathrm{pH}$ was 5 . The degradation effect of the chitosan, naproxen as well as naproxen/chitosan nanocapsule on the DNA in vitro. Chitosan as a macromolecule has no degradation effect on the DNA, naproxen alone has a significant degradation effect on the DNA while a complete degradation effect was exhibited by naproxen/chitosan nanocapsule. Chitosan has no effect on the BSA while, naproxen exhibited a little degradation effect on the BSA. However, the naproxen/chitosan nanocapsule exhibited a partial degradation effect on the BSA. The SOD mimics like activity of chitosan, naproxen, and naproxen/chitosan nanocapsule exhibit a significant SOD like activity and cause an inhibition percent of $78.01 \%, 66.61 \%$ and $72.07 \%$, respectively. The naproxen/chitosan nanocapsule has maximal antimicrobial activity with inhibition zone diameter against $E$. coli $27 \mathrm{~mm}, P$. aeruginosa $26 \mathrm{~mm}, B$. subtilis $23 \mathrm{~mm}$, S. aureus $27 \mathrm{~mm}$ and $S$. cerevisiae $24 \mathrm{~mm}$. Also, Chitosan showed a wide spectrum of antimicrobial activity with inhibition zone diameter against E. coli $25 \mathrm{~mm}, P$. aeruginosa $23 \mathrm{~mm}, B$. subtilis $24 \mathrm{~mm}$, S. aureus $24 \mathrm{~mm}$ and $S$. cerevisiae $20 \mathrm{~mm}$. However, the naproxen exhibited a moderate antimicrobial activity as the inhibition zone diameter against the tested microorganisms compared to the wide spectrum standard antibiotic ampicillin.

\section{References}

[1] Juang, R.S., Wu, F.C. and Tseng, R.L. (2001) Solute Adsorption and Enzyme Immobilizationon Chitosan Beads Prepared from Shrimp Shell Wastes. Bioresource Technology, 80, 187-193. http://dx.doi.org/10.1016/S0960-8524(01)00090-6

[2] Monteiro, O.A. and Airoldi, C. (1999) Some Studies of Crosslinking Chitosan Glutaraldehyde Interaction of Homogeneous System. International Journal of Biological Macromolecules, 26, 119-128. http://dx.doi.org/10.1016/S0141-8130(99)00068-9

[3] Denkbas, E.B., Kilicay, E., Birlikseven, C. and Ozturk, E. (2002) Magnetic Chitosan Microspheres: Preparation and Characterization. Reactive and Functional Polymers, 50, 225-232. http://dx.doi.org/10.1016/S1381-5148(01)00115-8

[4] Selmer-Olsen, E., Ratnaweera, H.C. and Pehrson, R. (1996) Novel Treatment Process for Dairy Wastewater with Chitosan Produced from Shrimp-Shell Waste. Water Science and Technology, 34, 33-40. http://dx.doi.org/10.1016/S0273-1223(96)00818-9

[5] Kucera, J. (2004) Fungal Myceliumthe Source of Chitosan for Chromatography. Journal of Chromatography B, 808, 69-73. http://dx.doi.org/10.1016/j.jchromb.2004.05.023

[6] Chiou, S.H. and Wu, W.T. (2004) Immobilization of Candida Rugosa Lipase on Chitosan with Activation of Hydroxyl Group. Biomaterials, 25, 197-204. http://dx.doi.org/10.1016/S0142-9612(03)00482-4

[7] Mi, F.L., Kuan, C.Y., Shyu, S.S., Lee, S.T. and Chang, S.F. (2000) The Study of Gelation Kinetics and Chain-Relaxation Properties of Glutaraldehyde-Cross-Linked Chitosan Gel and Their Effects on Microspheres Preparation and Drug Release. Carbohydrate Polymers, 41, 389-396. http://dx.doi.org/10.1016/S0144-8617(99)00104-6

[8] Berthold, A., Cremer, K. and Kreuter, J. (1996) Preparation and Characterization of Chitosan Microspheres as Drug 
Carrier for Prednisolone Sodium Phosphate as Model for Anti-Inflammatory Drugs. Journal of Controlled Release, 39, 17-25. http://dx.doi.org/10.1016/0168-3659(95)00129-8

[9] Tian, X.X. and Groves, M.J. (1999) Formulation and Biological Activity of Antineoplastic Proteoglycans Derived from Mycobacterium vaccae in Chitosan Nanoparticles. Journal of Pharmacology and Pharmacotherapeutics, 51, 151-157. http://dx.doi.org/10.1211/0022357991772268

[10] Du, J., Chen, Y., Han, C. and Schmidt, M. (2003) Organic/Inorganic Hybrid Vesicles Based on a Reactive Block Copolymer. Journal of the American Chemical Society, 125, 14710-14711. http://dx.doi.org/10.1021/ja0368610

[11] Clark, C.G. and Wooley, K.L. (2001) Dendrimers and Other Dendritic Polymers. In: Tomalia, D.A., Ed., Regioselectively-Crosslinked Nanostructures, Wiley, New York, 166-174.

[12] Peyratout, C.S. and Dahne, L. (2004) Tailor-Made Polyelectrolyte Microcapsules: From Multilayers to Smart Containers. Angewandte Chemie International Edition, 43, 3762-3783. http://dx.doi.org/10.1002/anie.200300568

[13] Sukhorukov, G.B., Rogach, A.L., Zebli, B., Liedl, T., Skirtach, A.G. and Parak, W.J. (2005) Nanoengineered Polymer Capsules: Tools for Detection, Controlled Delivery, and Site-Specific Manipulation. Small, 1, 194-200. http://dx.doi.org/10.1002/smll.200400075

[14] Bédard, M.F., De Geest, B.G., Skirtach, A.G., Möhwaldb, H. and Sukhorukov, G.B. (2010) Polymeric Microcapsules with Light Responsive Properties for Encapsulation and Release. Advances in Colloid and Interface Science, 158, 2-14. http://dx.doi.org/10.1016/j.cis.2009.07.007

[15] Li, X.D., Lu, T., Xu, J.J., Hu, Q.L. and Shen, J.C. (2009) A Study of Properties of “Micelle-Enhanced” Polyelectrolyte Capsules: Structure, Encapsulation and in Vitro Release. Acta Biomaterialia, 5, 2122-2131. http://dx.doi.org/10.1016/j.actbio.2009.01.045

[16] Li, G., Feng, Y.Q., Gao, P. and Li, X.G. (2008) Preparation of Mono-Dispersed Polyurea-Urea Formaldehyde Double Layered Microcapsules. Polymer Bulletin, 60, 725-731. http://dx.doi.org/10.1007/s00289-008-0894-x

[17] Zhao, M.W., Zheng, L.Q., Bai, X.T., Li, N. and Yu, L. (2009) Fabrication of Silica Nanoparticles and Hollow Spheres Using Ionic Liquid Microemulsion Droplets as Temdishes. Colloids and Surfaces A: Physicochemical and Engineering Aspects, 346, 229-236. http://dx.doi.org/10.1016/j.colsurfa.2009.06.021

[18] Zhang, K., Zheng, L.L., Zhang, X.H., Chen, X. and Yang, B. (2006) Silica-PMMA Core-Shell and Hollow Nanospheres. Colloids and Surfaces A: Physicochemical and Engineering Aspects, 277, 145-150. http://dx.doi.org/10.1016/j.colsurfa.2005.11.049

[19] Liu, H.X., Wang, C.Y., Gao, Q.X., Chen, J.X., Ren, B.Y. and Tong, Z. (2009) Facile Fabrication of Well-Defined Hydrogel Beads with Magnetic Nanocomposite Shells. International Journal of Pharmaceutics, 376, 92-98. http://dx.doi.org/10.1016/j.ijpharm.2009.04.031

[20] Szarpak, A., Cui, D., Dubreuil, F., De Geest, B.G., De Cock, L.J., Picart, C. and Ly-Velty, R.A. (2010) Designing Hyaluronic Acid-Based Layer-by-Layer Capsules as a Carrier for Intracellular Drug Delivery. Biomacromolecules, 11, 713-720. http://dx.doi.org/10.1021/bm9012937

[21] Endo, Y., Sato, K. and Anzai, J.I. (2010) Preparation of Avidin-Containing Polyelectrolyte Microcapsules and Their Uptake and Release Properties. Polymer Bulletin, 66, 711-720. http://dx.doi.org/10.1007/s00289-010-0375-X

[22] Taqieddin, E. and Amiji, M. (2004) Enzyme Immobilization in Novel Alginate-Chitosan Core-Shell Microcapsules. Biomaterials, 25, 1937-1942. http://dx.doi.org/10.1016/j.biomaterials.2003.08.034

[23] Tang, Y.F., Zhao, Y.Y., Li, Y. and Du, Y.M. (2010) A Thermo-Sensitive Chitosan/Poly(Vinyl Alcohol) Hydrogel Containing Nanoparticles for Drug Delivery. Polymer Bulletin, 64, 791-804. http://dx.doi.org/10.1007/s00289-009-0214-0

[24] Harrington, P.J. and Lodewijk, E. (1997) Large-Scale Synthetic Process for (S)-Naproxen by Syntex. Organic Process Research Development, 1, 72-76. http://dx.doi.org/10.1021/op960009e

[25] Rollas, S. and Kucukguzel, S.G. (2007) Biological Activities of Hydrazone Derivatives. Molecules, 12, $1910-1939$. http://dx.doi.org/10.3390/12081910

[26] Sriram, D., Yogeeswari, P. and Devakaram, R.V. (2006) Synthesis, in Vitro and in Vivo Antimycobacterial Activities of Diclofenac Acid Hydrazones and Amides. Bioorganic Medicinal Chemistry, 14, 3113-3118. http://dx.doi.org/10.1016/j.bmc.2005.12.042

[27] Munoz-Muniz, O. and Juaristi, E. (2003) Enantioselective Protonation of Prochiralenolates in the Asymmetric Synthesis of (S)-Naproxen. Tetrahedron Letters, 44, 2023-2026. http://dx.doi.org/10.1016/S0040-4039(03)00217-X

[28] Tang, Z.X., Qian, J.Q. and Shi, L.E. (2007) Preparation of Chitosan Nanoparticles as Carrier for Immobilized Enzyme. Applied Biochemistry and Biotechnology, 136, 77-97. http://dx.doi.org/10.1007/BF02685940

[29] Syedakulsum, Padmalatha, M., Sandeep, K., Saptasila, B. and Vidyasagar, G. (2011) Spectrophotometric Methods for the Determination of Naproxen sodium in Pure and Pharmaceutical Dosage Forms. International Journal of Research 
in Pharmaceutical and Biomedical Sciences, 2, 1303-1307.

[30] Genthner, F.J., Hook, L.A. and Strohl, W.R. (1985) Determination of the Molecular Mass of Bacterial Genomic DNA and Plasmid Copy Number by High-Pressure Liquid Chromatography. Applied and Environmental Microbiology, 50, 1007-1013.

[31] Sambrook, J., Fritsch, E.F. and Maniatis, T. (1989) Molecular Cloning: A Laboratory Manual. Cold Spring Harbor Laboratory Press, Cold Spring Harbor.

[32] Laemmli, U.K. (1970) Cleavage of Structural Proteins during the Assembly of the Head of Bacteriophage T4. Nature, 227, 680-685.

[33] Bauer, A.W., Kirby, W.M., Sherris, J.C. and Turck, M. (1966) Antibiotic Susceptibility Testing by a Standardized Single Disk Method. Journal of Clinical Pathology, 45, 493-496. http://dx.doi.org/10.1038/227680a0

[34] Bridges, S.M. and Salin, M.L. (1981) Distribution of Iron Containing Superoxide Dismutase in Vascular Plants. Plant Physiology, 68, 275-278. http://dx.doi.org/10.1104/pp.68.2.275 
Scientific Research Publishing (SCIRP) is one of the largest Open Access journal publishers. It is currently publishing more than 200 open access, online, peer-reviewed journals covering a wide range of academic disciplines. SCIRP serves the worldwide academic communities and contributes to the progress and application of science with its publication.

Other selected journals from SCIRP are listed as below. Submit your manuscript to us via either submit@scirp.org or Online Submission Portal.
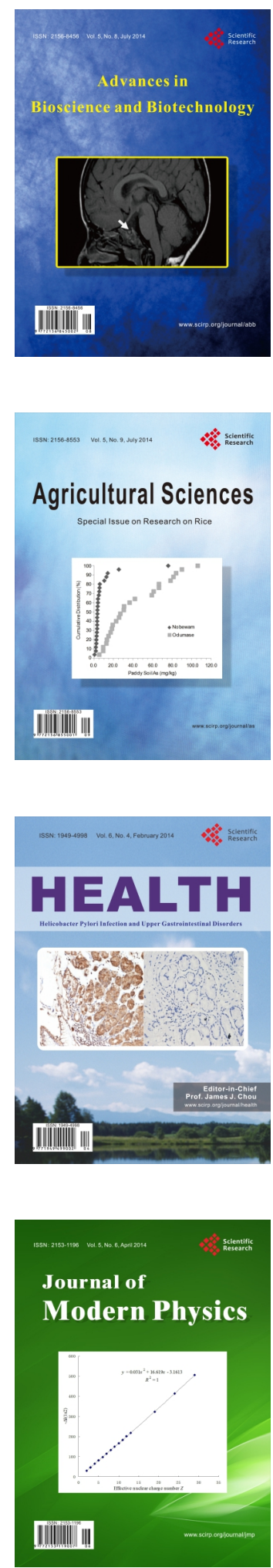
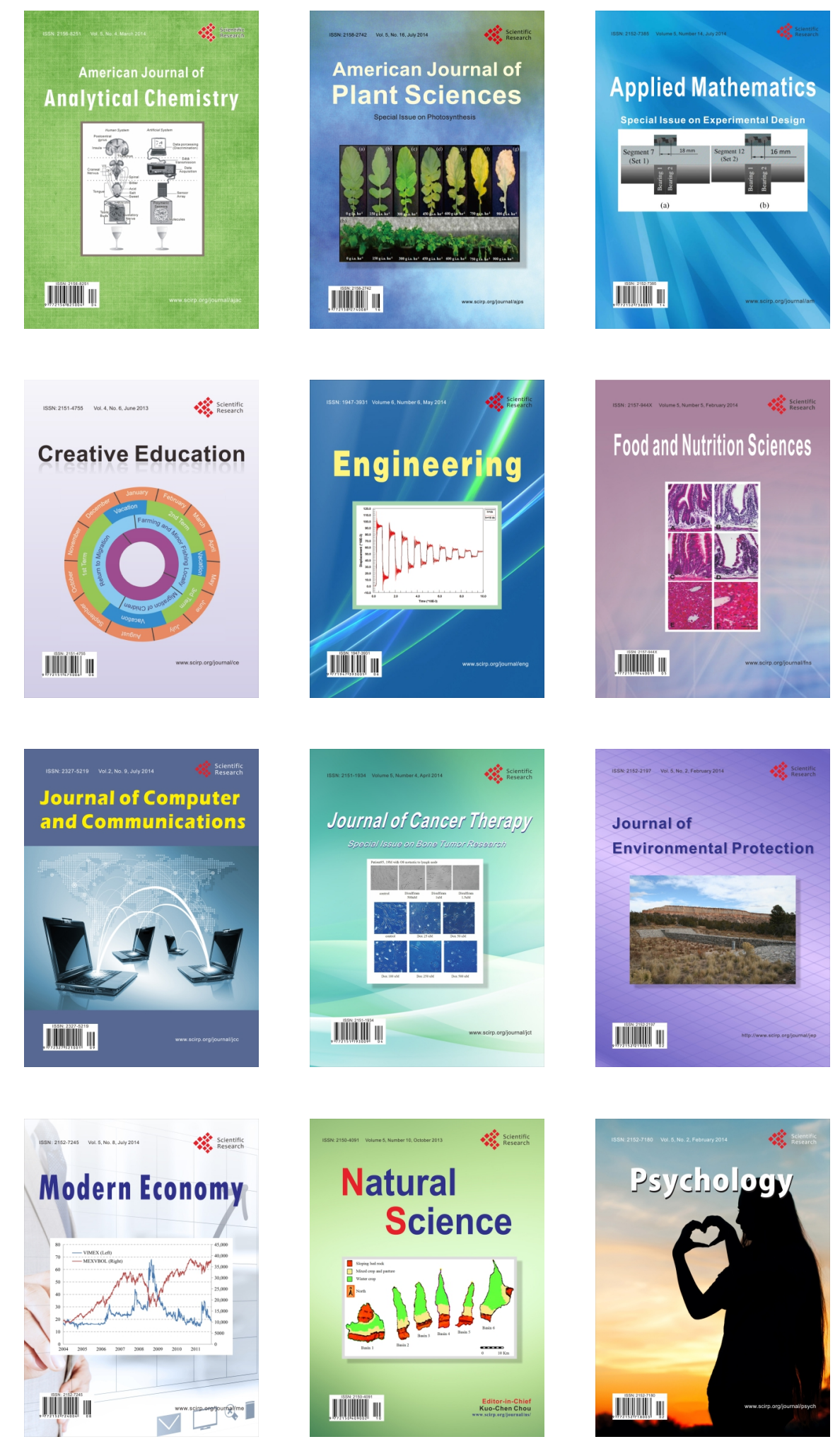